\title{
The Evaluation of an Environmental Regime in Taiwan's Adhesive Tape Manufacturing Industry
}

\author{
Ming-Chung Chang ${ }^{1}$ \\ ${ }^{1}$ Department of Banking and Finance, Kainan University, Taiwan \\ Correspondence: Ming-Chung Chang, Department of Banking and Finance, Kainan University, No. 1 Kainan \\ Road, Luchu, Taoyuan County 33857, Taiwan. Tel: 886-3-341-2500 ext. 6212. E-mail: \\ changme@mail.knu.edu.tw
}

Received: December 8, 2012

Accepted: December 26, 2012

Online Published: January 31, 2013

doi:10.5539/ibr.v6n3p154

URL: http://dx.doi.org/10.5539/ibr.v6n3p154

\begin{abstract}
Many governments set up different environmental regimes with respect to different industries. Taiwan's government uses the environmental standard regime to regulate the adhesive tape manufacturing industry and the emission tax regime to regulate the cement manufacturing industry. We here are interested about whether the environmental standard is the welfare-superior regime to Taiwan's adhesive tape manufacturing industry. Our study shows that the environmental standard may not be a welfare-superior regime to this industry. This result is different from Naito and Ogawa (2009) who consider the relation between the environmental regime and the privatization degree. We also conclude there is an environmental preference inconsistency between the patentee and the social planner when the innovator is a domestic firm.
\end{abstract}

Keywords: technology transfer, innovation, environmental instruments

\section{Introduction}

In a product's production process, many materials are emitted to the atmosphere directly or are an indirect threat to a human being's life. For reducing harmful ambient emissions, the effective way is either a market-based mechanism or a command and control tool. The Clean Air Act in the United States gives the Environmental Protection Agency (EPA) a mandate to implement market-based mechanisms, such as emissions taxes and trading programs. The command and control tool, such as the environmental standard, is used by Taiwan's Environmental Protection Administration (TEPA) to regulate the adhesive tape manufacturing industry, because this industry emits a pollutant and toxic material called Volatile Organic Compounds (VOCs) that damage a human's brain, liver, and central nervous system. With the passage of the 2010 Amendments to Taiwan's emissions regulations on the adhesive tape manufacturing industry, Taiwan's legislative Yuan gave the TEPA a mandate to regulate VOCs emissions in the adhesive tape manufacturing industry.

The market structure of Taiwan' adhesive tape manufacturing industry is an oligopoly. To help reduce VOCs emissions and manufacture an environmentally friendly product, Taiwan's Industrial Technology Research Institute (TITRI) announces environmentally friendly technologies on its website and licenses them to Taiwan's adhesive tape manufacturing firms. Taiwan's adhesive tape manufacturing firms also seek environmentally friendly technologies from foreign adhesive tape manufacturing firms, such as Minnesota Mining and Manufacturing Company (3M) and Japan Kikusui Tape Company. The motivation of this study is to examine whether Taiwan's emission regulation on the adhesive tape manufacturing industry creates high social welfare. We also care about the environmental policy's consistency between the patentee and the social planner. We find that Taiwan's emission regulation on this industry may not maximize Taiwan's social welfare. Moreover, there is an environmental preference inconsistency between the patentee and the social planner.

Based on Taiwan's adhesive tape manufacturing industry, we examine two kinds of environmental regimes, i.e., the emission tax regime and the environmental standard regime, in order to find the welfare-superior environmental regime. The previous literature only discusses the effect of one kind of environmental instrument, such Ebert (1992) examining the effect of emission abatement under an emission tax regime in different oligopoly models. Ebert (1998) also analyzes the effect of an environmental standard in a homogeneous Cournot oligopoly model. Katsoulacos and Xepapadeas (1995) investigate the effects of the emission tax regime when the number of firms is fixed or the firms are allowed to enter and exit the market freely. They conclude that the emission tax 
regime creates an emission externality caused by over-internalization when firms are allowed to enter and exit the market freely. Kayalica and Lahiri (2005) discuss the optimal environmental policy when the foreign firm conducts direct investments, finding that the host government should adopt a (not) strict environmental standard when the number of foreign firms that directly invest is (not) fixed.

The other part of the literature that only considers the effect of one kind of environmental policies includes Bárcena-Ruiz and Garzó (2006), Beladi and Chao (2006), Kato (2006), Ohori (2006a; 2006b), and Wang and Wang (2009). Some previous studies also investigate which type of environmental regulation is desirable in terms of social welfare, such as Spulber (1985), Kiyono and Okuno-Fujiwara (2003), Lahiri and Ono (2007), Naito and Ogawa (2009), and Kato (2011). This paper is most similar with Naito and Ogawa (2009) in which they investigate the welfare-superior environmental regime. They conclude that the emission standard regime is better for social welfare than an emission tax regime no matter what the partial privatization degree is. Our paper investigates which environmental regime is better for social welfare when the firms enact a technology transfer behavior. We take Taiwan's adhesive tape manufacturing industry as an example to find the welfare-superior environmental regime.

The relation between the environmental instrument and the environmental protection effect is an important issue in the previous literature. Helfand (1991) uses the ratio of total emission divided by total output as an environmental standard. He believes that a strict environmental standard may cause the amount of emission to increase since firms can increase their output instead of decreasing their emission to reach a regulated environmental standard. Thus, the emission tax is a better environmental instrument than the environmental standard. Ulph (1996) examines the impact of the emission tax regime and the environmental standard regime on social welfare in an imperfectly competitive international trade market. He concludes that either the emission tax regime or the environmental standard regime can create higher social welfare, yet it depends on whether all countries' governments or a part of the governments adopt an emission abatement action. Spulber (1985) concludes that the emission tax regime is more efficient than the environmental standard regime on environmental protection when firms are allowed to enter and exit the market freely. Lahiri and Ono (2007) investigates the social welfare and the emission level between the emission tax regime and the environmental standard regime. They conclude that when the number of firms is fixed, social welfare in the environmental standard regime is higher than that in the emission tax regime, whereas the emission level in the environmental tax regime is lower than that in the environmental standard regime. However, the results above are inversed when firms are allowed to enter and exit the market freely and when the demand function is concave.

For a green production target, we not only can adopt an appropriate environmental instrument, but also use an emission abatement technology. The previous literature just focuses on the application of the environmental instrument, but ignores that the emission abatement technology transformation can also reach the environmental protection target. Generally speaking, the licensing method includes fixed fee, royalty rate, auction, etc. Kamien and Tauman (1984) are the first to discuss the issue of technology transformation. In their paper, the innovator that does not join the product's market competition is called the outside innovator whose mission is only to conduct research and development (R\&D) and then to sell a new technology, such as Taiwan's Industry Technology Research Institution. Based on this line, Kamien and Tauman (1984, 1986), Katz and Shapiro (1986), Kamien et al. (1992), and Wang (1998) conclude that when an outside innovator licenses a non-drastic innovation, the optimal licensing mode is a fixed fee licensing contract. (Note 1)

The technology licensing issue has been extended into many various fields, such as when the technology licensing occurs in an open economy (Mukherjee, 2007; Chang, 2011), an innovator licenses a new technology about product quality (Li \& Song, 2009), the technology licensing occurs in vertical market structure (Brocas, 2003; Matsushima, 2004; Buehler \& Schmutzler, 2007), using the spatial competition model to discuss the technology licensing (Poddar \& Sinha, 2004; Lin et al., 2012), and the technology licensing occurs when the number of licensee is extended to $n$ firms, where $n \geq 3$ (Kamien \& Tauman, 2002; Sen, 2005). A few technology licensing papers touch upon the environmental protection issue. To our best knowledge, Chang et al. (2009) is one paper about environmental technology licensing in which they investigate the optimal mode of environmental technology licensing in a homogeneous Cournot duopoly. They conclude that a high emission tax in the fixed-fee licensing contract may disrupt environmental technology licensing between licensor and licensee. More specifically, a large size of environmental technology innovation is not necessary to induce a maximized social welfare. Their model set-up is a closed economy, the licensor is an inside innovator, and the government's environmental policy only has the emission tax. However, the model set-up in our paper is an open economy, the licensor is an outside innovator, and the government has two environmental policies: the emission tax and the environmental standard. More specifically, the outside innovator can choose to license to one firm or 
to license to two firms.

We use the concept of emission-equivalent to find the welfare-superior environmental regime. We also compare the environmental policy preference between the patentee and the social planner. We find that the environmental standard regime on Taiwan's adhesive tape manufacturing industry may not be a welfare-superior environmental regime. This finding is different from Naito and Ogawa (2009) who examine the relation between the environmental regime and the privatization degree. We also find there is environmental preference inconsistency between the patentee and the social planner when the innovator is a domestic firm.

The remainder of this paper is organized as follows: Section 2 is the model set-up. Section 3 shows the model solution. Section 4 demonstrates social welfare analysis. Section 5 is the model extension. The findings are concluded in Section 6.

\section{Model Set-Up}

Our model includes two domestic firms producing homogeneous production, a foreign innovator having an emission abatement technology (this assumption will be relaxed in Section 5) and a domestic government choosing an environmental regime for maximizing social welfare. The foreign firm is an outside innovator that does not make the product, and just licenses an emission abatement technology to domestic firms. We use a two-stage game to describe the decision-making of the domestic firms, the licensor, and the domestic government. In Stage 0, the domestic government chooses either an emission tax regime or an environmental standard regime to maximize social welfare. In Stage 1, the licensor chooses the optimal licensing proportion $\phi=$ $\{0\},\{1 / 2\}$, or $\{1\}$ to transfer an emission abatement technology by means of a fixed-fee licensing method for maximizing the licensing revenue. If there is a $2 \phi$ firm with an emission abatement technology, then there is a $2(1-\phi)$ firm without an emission abatement technology. In Stage 2, two domestic firms conduct a homogeneous Cournot competition. We use backward induction to solve the sub-game perfect Nash equilibrium (SPNE). It is valuable to mention why we choose the fixed-fee as a licensing method. The reason is that the patentee in our paper is an outside innovator and Kamien and Tauman (1986) show that the outside patentee always prefers the fixed-fee licensing method.

We assume that each product creates $e>0$ unit emission in a production process, and parameter $e$ is normalized to 1 for a simplified analysis. An emission abatement technology reduces each unit emission from 1 to $1-\varepsilon$, where $\varepsilon \in[0,1]$ and the parameter $\varepsilon$ is defined as the innovation size. We hereafter use the symbol "*" to label the variables in an environmental standard regime, and the variables without the symbol "*" stand for the case in an emission tax regime.

A regulated environmental standard $z$ represents each unit product's maximum allowed emission amount. In other words, a small (large) parameter $z$ means a (not) strict environmental standard. In an environmental standard regime, each unit product's emission abatement amount for a firm with an emission abatement technology is $(1-\varepsilon)-z$; if a firm is without an emission abatement technology, then it has to reduce the emission amount from 1 to $1-z$. We assume that the emission abatement cost of each unit product is $\theta$. Thus, each unit product's emission abatement cost for the firm without (with) an emission abatement technology is $c_{0}{ }^{*}$ $=\theta(1-z)\left(c_{1}{ }^{*}=\theta(1-\varepsilon-z)\right)$. Without changing the equilibrium result, we normalize parameter $\theta$ to be 1 and get $c_{0}{ }^{*}=1-z$ and $c_{1}{ }^{*}=1-\varepsilon-z$. In an emission tax regime, the government levies an emission tax rate $t$ on each unit emission amount. Each unit emission cost for a firm without (with) an emission abatement technology is $c_{0}$ $=t\left(c_{1}=t(1-\varepsilon)\right)$. Since we focus on an environmental regime analysis, we ignore the firms' production cost.

\section{Model Solution}

This section shows the SPNE in Stage 1 and Stage 2 in the emission tax regime and the environmental standard regime.

\subsection{The Emission Tax Regime}

The product's demand function has a linear form, i.e., $p=a-b Q$, where the parameters $p$ and $Q$ are the product's market price and the product's quantity, respectively. The quantity $Q=\left\{2 x_{0}\right\},\left\{x_{0}^{\prime}+x_{1}{ }^{\prime}\right\}$, or $\left\{2 x_{1}\right\}$, where $x_{0}\left(x_{1}\right)$ is each firm's output when $\phi=0(1)$, and $x_{0}^{\prime}$ and $x_{1}^{\prime}$ are respectively the non-licensee's output quantity and the licensee's output quantity when $\phi=1 / 2$. The variable $x_{1}{ }^{m}\left(\pi_{1}{ }^{m}\right)$ represents a monopoly output quantity (profit), which occurs when the innovation size is large enough and the patentee only licenses the emission abatement technology to only one firm, i.e., $\phi=1 / 2$. Let $x_{0}{ }^{\prime}=0$ and then we obtain the drastic innovation condition to be $\varepsilon>(a-t) / t$; on the contrary, a non-drastic innovation condition is $0<\varepsilon<(a-t) / t$. The solutions in Stage 2 are arranged in Table 1. 
Table 1. The results of Stage 2 under an emission tax regime

\begin{tabular}{|c|c|c|c|}
\hline Innovation size & & quantity & profit \\
\hline \multirow{3}{*}{$\begin{array}{l}0<\varepsilon<\frac{a-t}{t} \\
\text { (non-drastic innovation) }\end{array}$} & $\phi=0$ & $x_{0}=\frac{a-t}{3 b}$ & $\pi_{0}=\frac{(a-t)^{2}}{9 b}$ \\
\hline & $\phi=1 / 2$ & $\begin{array}{l}x_{0}^{\prime}=\frac{a-t-t \varepsilon}{3 b} \\
x_{1}^{\prime}=\frac{a-t+2 t \varepsilon}{3 b}\end{array}$ & $\begin{array}{l}\pi_{0}^{\prime}=\frac{(a-t-t \varepsilon)^{2}}{9 b} \\
\pi_{1}^{\prime}=\frac{(a-t+2 t \varepsilon)^{2}}{9 b}\end{array}$ \\
\hline & $\phi=1$ & $x_{1}=\frac{a-t+t \varepsilon}{3 b}$ & $\pi_{1}=\frac{(a-t+t \varepsilon)^{2}}{9 b}$ \\
\hline $\begin{array}{l}\varepsilon>\frac{a-t}{t} \\
\text { (drastic innovation) }\end{array}$ & & $x_{1}^{m}=\frac{a-t+t \varepsilon}{2 b}$ & $\pi_{1}^{m}=\frac{(a-t+t \varepsilon)^{2}}{4 b}$ \\
\hline
\end{tabular}

Through a competitive static analysis with respect to the results in Stage 2, we find $d x_{0} / d t<0$ and $d x_{0}^{\prime} / d t<0$, which imply that a non-licensee's output quantity decreases when the emission tax rate increases. The result is caused by a cost increase. However, the impact of the emission tax rate on the licensees' output quantity is:

$$
\begin{gathered}
\frac{d x_{1}}{d t}=\frac{-(1-\varepsilon)}{3 b}<0 \\
\frac{d x_{1}^{\prime}}{d t}=\frac{-(1-2 \varepsilon)}{3 b}>0, \text { if } \varepsilon>1 / 2 \\
\frac{d x_{1}^{m}}{d t}=\frac{-(1-\varepsilon)}{2 b}<0
\end{gathered}
$$

A specific result is in Equation (1b), showing that if only one firm is licensed and the innovation size is sufficiently large, then the licensee's output quantity increases when the emission tax rate increases. The result in Equation (1b) comes from the innovation size effect being larger than the cost increase effect.

We next examine the result in Stage 1 where the licensor decides the licensing proportion. Since the licensor's licensing revenue is defined as the difference between the licensee's profit with licensing and the licensee's profit

\begin{tabular}{|c|c|c|}
\hline Innovation size & & Licensor's licensing revenue \\
\hline \multirow{3}{*}{$\begin{array}{l}0<\varepsilon<\frac{a-t}{t} \\
\text { (non-drastic innovation) }\end{array}$} & $\phi=0$ & $R_{0}=0$ \\
\hline & $\phi=1 / 2$ & $R_{1}^{\prime}=\pi_{1}^{\prime}-\pi_{0}=\frac{4 t \varepsilon(a-t+t \varepsilon)}{9 b}>0$ \\
\hline & $\phi=1$ & $R_{1}=2\left(\pi_{1}-\pi_{0}\right)=2\left[\frac{t \varepsilon(2 a-2 t+t \varepsilon)}{9 b}\right]>0$ \\
\hline $\begin{array}{l}\varepsilon>\frac{a-t}{t} \\
\text { (drastic innovation) }\end{array}$ & & $R_{1}{ }^{m}=\pi_{1}^{m}-\pi_{0}=\frac{(a-t+t \varepsilon)^{2}}{4 b}-\frac{(a-t)^{2}}{9 b}>0$ \\
\hline
\end{tabular}
without licensing, the licensing revenue for the patentee is represented in Table 2.

Table 2. Licensor's licensing revenue under an emission tax regime

Since the licensor's licensing revenue is positive, the licensor prefers to license; and the licensee's profit after accepting licensing will not worsen, and thus the licensee prefers to accept the offer. By a simple calculation for finding the solution in Stage 1, we obtain $R_{1}{ }^{\prime}-R_{1}=2(t \varepsilon)^{2} /(9 b)>0$, and $R_{1}{ }^{m}$ must be larger than $R_{1}$. The solution in Stage 1 is summarized as follows:

$$
\phi=1 / 2 \text { for all } \varepsilon>0
$$

\subsection{The Environmental Standard Regime}

In an environmental standard regime, the firms' output decision in Stage 2 is arranged in Table 3. 
Table 3. The results of Stage 2 under an environmental standard regime

\begin{tabular}{|c|c|c|c|}
\hline Innovation size & & quantity & profit \\
\hline \multirow{3}{*}{$\begin{array}{l}0<\varepsilon<a-(1-z) \\
\text { (non-drastic innovation) }\end{array}$} & $\phi=0$ & $x_{0}{ }^{*}=\frac{a-(1-z)}{3 b}$ & $\pi_{0}^{*}=\frac{[a-(1-z)]^{2}}{9 b}$ \\
\hline & $\phi=1 / 2$ & $\begin{array}{l}x_{0}{ }^{\prime *}=\frac{a-(1-z)-\varepsilon}{3 b} \\
x_{1}{ }^{\prime *}=\frac{a-(1-z)+2 \varepsilon}{3 b}\end{array}$ & $\begin{array}{l}\pi_{0}^{\prime *}=\frac{[a-(1-z)-\varepsilon]^{2}}{9 b} \\
\pi_{1}^{\prime *}=\frac{[a-(1-z)+2 \varepsilon]^{2}}{9 b}\end{array}$ \\
\hline & $\phi=1$ & $x_{1}^{*}=\frac{a-(1-\varepsilon-z)}{3 b}$ & $\pi_{1}^{*}=\frac{[a-(1-z)+\varepsilon]^{2}}{9 b}$ \\
\hline $\begin{array}{l}\varepsilon>a-(1-z) \\
\text { (drastic innovation) }\end{array}$ & & $x_{1}^{m^{*}}=\frac{a-(1-\varepsilon-z)}{2 b}$ & $\pi_{1}^{m^{*}}=\frac{[a-(1-z)+\varepsilon]^{2}}{4 b}$ \\
\hline
\end{tabular}

Some results of comparative static analysis in Stage 2 are represented as follows:

$$
\begin{gathered}
\frac{d x_{0}^{*}}{d z}=\frac{d x_{0}^{\prime *}}{d z}=\frac{d x_{1}^{*}}{d z}=\frac{d x_{1}^{\prime *}}{d z}=\frac{1}{3 b}>0 \\
\frac{d x_{1}^{m^{*}}}{d z}=\frac{1}{2 b}>0
\end{gathered}
$$

Equation (3) shows that the non-licensee's and the licensee's outputs decrease when the environmental standard becomes strict. However, it is valuable to notice that there is no innovation size effect on the licensee's output when the environmental standard does become strict. This result is very different with that in the emission tax regime.

We present Table 4 to show the results of the patentee's licensing revenue in the environmental standard regime.

\begin{tabular}{|c|c|c|}
\hline Innovation size & & Licensor's licensing revenue \\
\hline \multirow{3}{*}{$\begin{array}{l}0<\varepsilon<a-(1-z) \\
\text { (non-drastic innovation) }\end{array}$} & $\phi=0$ & $R_{0}^{*}=0$ \\
\hline & $\phi=1 / 2$ & $R_{1}^{\prime *}=\pi_{1}^{\prime *}-\pi_{0}^{*}=\frac{4 \varepsilon[a-(1-z)+\varepsilon]}{9 b}>0$ \\
\hline & $\phi=1$ & $R_{1}{ }^{*}=2\left(\pi_{1}{ }^{*}-\pi_{0}{ }^{*}\right)=\frac{2 \varepsilon[2 a-2(1-z)+\varepsilon]}{9 b}>0$ \\
\hline $\begin{array}{l}\varepsilon>a-(1-z) \\
\text { (drastic innovation) }\end{array}$ & & $\begin{array}{l}R_{1}^{m^{*}}=\pi_{1}^{m^{*}}-\pi_{0}^{*} \\
=\frac{[a-(1-z)+\varepsilon]^{2}}{4 b}-\frac{[a-(1-z)]^{2}}{9 b}>0\end{array}$ \\
\hline
\end{tabular}

Table 4. Licensor's licensing revenue under an environmental standard regime

By a simple calculation, we get $R_{1}{ }^{*}-R_{1}{ }^{*}=2 \varepsilon^{2} /(9 b)>0$, and $R_{1}{ }^{{ }^{*}}$ must be larger than $R_{1}{ }^{\prime *}$. The solution in Stage 1 is summarized as follows:

\subsection{An Emission-Equivalent Analysis}

TEPA adopts the environmental standard regime to regulate VOCs emissions from Taiwan's adhesive tape manufacturing industry. We are interested in whether the environmental standard regime is a welfare-superior environmental regime. In order to examine this question, we use the concept of emission-equivalent, which means that the emission amount in the emission tax regime is the same as that in the environmental standard regime. Since we assume that one unit product creates one unit emission, the total emission amount is equal to the total output quantity. The emission-equivalent conditions in the two environmental regimes are shown in Table 5. 
Table 5. The emission-equivalent conditions in the two environmental regimes

\begin{tabular}{llll}
\hline & & \multicolumn{2}{l}{ Amount of emission under an emission tax rate regime } \\
\cline { 2 - 4 } & & $\begin{array}{l}\text { Non-drastic innovation } \\
\left(E^{\prime}=x_{0}{ }^{\prime}+x_{1}{ }^{\prime}\right)\end{array}$ & $\begin{array}{l}\text { Drastic innovation } \\
\left(E^{m}=x_{1}{ }^{m}\right)\end{array}$ \\
\hline \multirow{2}{*}{$\begin{array}{l}\text { Amount of emission } \\
\text { under an environmental } \\
\text { standard regime }\end{array}$} & $\begin{array}{l}\text { Non-drastic innovation } \\
\left(E^{*}=x_{0}{ }^{* *}+x_{1}^{\prime *}\right)\end{array}$ & $t=1-\frac{2}{2-\varepsilon} z$ & - \\
\cline { 2 - 4 } & $\begin{array}{l}\text { Drastic innovation } \\
\left(E^{m^{*}}=x_{1}{ }^{m^{*}}\right)\end{array}$ & - & $t=1-\frac{1}{1-\varepsilon} z$ \\
\hline
\end{tabular}

In Table 5 we find that the emission-equivalent condition in a non-drastic innovation situation is $t=1-[2 /(2-$ $\varepsilon)] z$, and the emission-equivalent condition in a drastic innovation situation is $t=1-[1 /(1-\varepsilon)] z$. These two emission-equivalent conditions have the same characteristic in that they are not affected by the market size, i.e., the parameter $a$, and a strict environmental standard corresponds to a high environmental tax rate.

\section{Social Welfare Analysis}

In this section we first define the social welfare functions in two kinds of different environmental regimes and then use them to discuss the government's environmental policy.

\subsection{Set-Up of the Social Welfare Function}

In the emission tax regime, the social welfare function $(S W)$ is composed of consumer surplus $(C S)$, producer surplus $(P S)$, emission tax revenue $(T)$, and environmental damage $(D)$, where $D^{\prime}>0$ and $D^{\prime \prime}>0$ (Kayalica \& Lahiri, 2005; Lahiri \& Ono, 2007). The social welfare function is expressed as $S W=C S+P S+T-D$. The consumer surplus in a linear demand form can be formulated as $(1 / 2) b Q^{2}$. The producer surplus is formulated by the sum of the two firms' profits. The emission tax revenue is $T=t E$, where $E$ is the total amount of emission and because of the assumption that one unit product creates one unit amount of emission, we have $E=Q$. The environmental damage is caused by the emission, and thus we have $D=(1 / 2) E^{2}$.

In the environmental standard regime, the social welfare function $\left(S W^{*}\right)$ is composed of consumer surplus $\left(C S^{*}\right)$, producer surplus $\left(P S^{*}\right)$, and environmental damage $\left(D^{*}\right)$. Hence, the social welfare function in the environmental standard regime is expressed as $S W^{*}=C S^{*}+P S^{*}-D^{*}$. According to the concept of emission-equivalent, we have $E=E^{*}, Q=Q^{*}, C S=C S^{*}, D=D^{*}$. Hence, the social welfare functions in these two environmental regimes can be rewritten as $S W=P S+T$, and $S W^{*}=P S^{*}$. By a comparison of the social welfare functions between the emission tax regime and the environmental standard regime, we find that although the social welfare function in the emission tax regime has an advantage on the tax revenue, the producer's surplus in the emission tax regime has a higher sensitivity than that in the environmental standard regime.

We next examine the social welfare difference between the emission tax regime and the environmental standard regime in a non-drastic innovation situation. The result is shown as follows:

$$
\begin{aligned}
\Delta S W^{n} & =S W^{n}-S W^{n^{*}}=\left(\pi_{0}^{\prime}+\pi_{1}^{\prime}\right)+t\left(x_{0}{ }^{\prime}+x_{1}{ }^{\prime}\right)-\left(\pi_{0}^{\prime *}+\pi_{1}^{\prime *}\right) \\
& =\left[\left(\pi_{1}^{\prime}-\pi_{1}^{\prime *}\right)+\left(\pi_{0}^{\prime}-\pi_{0}^{\prime *}\right)\right]+t\left(x_{0}^{\prime}+x_{1}^{\prime}\right) \\
& =\frac{2 \varepsilon^{2} z(\varepsilon+z-2)}{b(2-\varepsilon)^{2}}+\frac{(2 a+\varepsilon+2 z-2)(2-\varepsilon-2 z)}{3 b(2-\varepsilon)} \\
& =\frac{6 \varepsilon^{2} z(\varepsilon+z-2)}{3 b(2-\varepsilon)^{2}}+\frac{(2-\varepsilon-2 z)(2-\varepsilon)(2 a+2 z+\varepsilon-2)}{3 b(2-\varepsilon)^{2}}
\end{aligned}
$$

where the superscript $n$ represents a non-drastic innovation case. Similarly, the social welfare difference between the emission tax regime and the environmental standard regime in a drastic innovation situation is:

$$
\begin{aligned}
\Delta S W^{d} & =S W^{d}-S W^{d^{*}}=\pi_{1}{ }^{m}+t x_{1}{ }^{m}-\pi_{1}{ }^{m}{ }^{*} \\
& =\frac{[a-(1-\varepsilon-z)](1-\varepsilon-z)}{2 b(1-\varepsilon)} \geq 0
\end{aligned}
$$

where the superscript $d$ represents a drastic innovation case.

\subsection{The Government Policy}

From Equation (5), we can examine the government's optimal environmental policy. 


\subsubsection{In a Non-Drastic Innovation Case}

The parameters $\varepsilon$ and $z$ in Equation (5a) must satisfy the non-drastic innovation condition, i.e., $0<\varepsilon<a-(1-$ $z$ ), the condition for a non-negative output quantity, i.e., $a-(1-z)-\varepsilon \geq 0$, the condition for a non-negative cost, i.e., $1-\varepsilon-z \geq 0$, and the condition for a non-negative emission tax rate, i.e., $0<\varepsilon<2(1-z)$. These conditions result in the terms $(\varepsilon+z-2)<0,(2-\varepsilon-2 z)>0$, and $(2 a+2 z+\varepsilon-2)>0$ in Equation (5a). For satisfying all conditions above, we find the range of parameter $a$ to be $a \in[(1-z)+\varepsilon, \infty)$. We also see that the first term in Equation (5a) is negative and the second term in Equation (5a) is positive. This result tells us the firm's profit in the emission tax regime is always smaller than that in the environmental standard regime induced by an output distortion from the emission tax regime.

Equation (5a) also shows that when the market size is large, i.e., the parameter $a \rightarrow \infty$, it causes $\Delta S W^{n}>0$; when the market size is small, i.e., the parameter $a \rightarrow(1-z)+\varepsilon$, it causes $\Delta S W^{n}<0$. The result implies that when the market size is large enough, social welfare in the emission tax regime is higher than that in the environmental standard regime. On the contrary, when the market size is small, the adoption of an environmental standard regime is superior to the adoption of an emission tax regime. This result is because the domestic licensee has to pay a large licensing fee to the foreign innovator when the market size is big. Since a higher licensing fee is paid to the foreign innovator, it will result in a greater loss on domestic social welfare. Hence, the adoption of an emission tax regime can maintain higher social welfare by keeping the emission tax revenue in the home country. Conversely, if the market size is small, then the foreign licensor receives a part of the licensing revenue. Moreover, there is no distortion on output quantity in the environmental standard regime. Hence, when the licensor is a foreign innovator, the environmental standard (emission tax) regime can create high social welfare in a small (large) market.

\subsubsection{In a Drastic Innovation Case}

Equation (5b) obviously shows that the social welfare difference must be positive since Equation (5b) needs to satisfy the condition of non-negative cost, i.e., $1-\varepsilon-z \geq 0$, and the condition of non-negative output quantity, i.e., $a-(1-\varepsilon-z) \geq 0$. This result tells us that the emission tax regime creates higher social welfare than that in the environmental standard regime when the innovation size is drastic. The intuition behind this result is that the licensee becomes a monopolist after getting the emission abatement technology and obtains the monopoly profit. However, the licensee will also be charged the full monopoly profit as the licensing fee by the foreign licensor. A high fixed licensing fee that the domestic licensee pays to the foreign licensor has a negative impact on domestic social welfare. Hence, the domestic government can create a lower fixed licensing fee by levying an emission tax on domestic firms. Since the stage when the domestic government decides the environmental regime is before the stage when the foreign licensor decides the amount of licensing fee, the domestic government has a first mover advantage to decide the optimal environmental regime for controlling the amount of licensing fee.

We now summarize the effects of the emission tax regime and the environmental standard regime as follows: when the innovator is a foreign firm, the target that the home country government sets as the emission tax rate is not only for increasing the licensee's competitive profit by differentiating the firms' marginal costs, but also for leaving more competitive profit in the home country through emission revenue. Hence, the foreign innovator's licensing revenue decreases. However, this effect does not exist in the environmental standard regime, because the environmental standard regime does not affect the firms' competitive behavior and the domestic government has no way to leave the firms' competitive profits by means of an environmental standard regime. Hence, the environmental standard regime results in a large domestic social welfare leakage. The proposition in this section is shown as follows.

Proposition 1 In a drastic innovation case, social welfare in the emission tax regime is always higher than that in the environmental standard regime. In a non-drastic innovation case, when the market size is large, the conclusion is the same as that in a drastic innovation case; when the market size is small, social welfare in the environmental standard regime is higher then that in the emission tax regime.

\section{Model Extension: Patentee Is a Domestic Innovator}

In this section we change the assumption that the patentee is a foreign innovator to another assumption that the patentee is a domestic innovator. This change induces that the domestic social welfare function must include the patentee's licensing revenue. Hence, in the emission tax regime the social welfare function (SS) is composed of consumer surplus, producer surplus, emission tax revenue, environmental damage, and the domestic innovator's licensing revenue. In the environmental standard regime, the social welfare function $\left(S S^{*}\right)$ is composed of consumer surplus, producer surplus, environmental damage, and the domestic innovator's licensing revenue. 
Following the analysis process in Section 4, we here respectively discuss the cases of non-drastic innovation and drastic innovation.

\subsection{In a Non-Drastic Innovation Situation}

Based on the concept of emission-equivalence, the social welfare difference between the emission tax regime and the environmental standard regime is:

$$
\begin{aligned}
\Delta S S^{n} & =\Delta S W^{n}+\left(R^{\prime}-R^{*}\right) \\
& =\Delta S W^{n}+\frac{(4 / 3) \varepsilon z(-2 a(2-\varepsilon)-4 z(1-\varepsilon)-\varepsilon(8-3 \varepsilon)+4)}{3 b(2-\varepsilon)^{2}}
\end{aligned}
$$

We first concentrate on the innovator's environmental regime preference by examining its licensing revenue. By Equation (6a) we find that the larger market size is, the higher the licensing revenue is in the environmental standard regime. This result comes from the environmental standard regime not making an output distortion. The licensor can get more licensing revenue under the environmental standard regime. Hence, we conclude that when the market size is sufficiently large, the domestic innovator prefers the environmental standard regime to the emission tax regime.

We next concentrate on the social planner's environmental regime preference by comparing the social welfare difference in two environmental regimes. The comparative static result on the social welfare difference is:

$$
\frac{d \Delta S S^{n}}{d a}=\frac{2(2-\varepsilon)(2-\varepsilon-2 z)}{3 b(2-\varepsilon)^{2}}+\frac{(4 / 3) \varepsilon z(2 \varepsilon-4)}{3 b(2-\varepsilon)^{2}} \geq 0, \text { if } \varepsilon \in\left[0, \frac{6(1-z)}{3+4 z}\right]
$$

From Equation (6b), we find given a small innovation size, when the market size is large, social welfare in the emission tax regime is higher than that in the environmental standard regime. This result is very different from the result of the previous section in a non-drastic innovation case in which the optimal environmental policy is only affected by the market size. However, the result of this section shows the optimal environmental policy is not only affected by the market size, but also by the innovation size, because a small innovation size only creates small licensing revenue for a licensor. However, the emission tax policy mitigates the firm's market competition and increases the licensee's profit. Since the licensee's profit increases, the patentee can charge a high licensing fee from the licensee. The adoption of an emission tax regime causes high industrial profit, a high licensing fee, and then induces high social welfare. On the other hand, given a large market size with a large innovation size, social welfare in the environmental standard regime is higher than that in the emission tax regime, because a large innovation size weakens the firm's market competition and increases the licensee's profit. Hence, a large market size and a large innovation size create a large producer surplus and high social welfare if the social planner adopts an environmental standard regime.

\subsection{In a Drastic Innovation Situation}

The social welfare difference between the emission tax regime and the environmental standard regime in this section is:

$$
\begin{aligned}
\Delta S S^{d} & =\Delta S W^{d}+\left(R^{m}-R^{m^{*}}\right) \\
& =\Delta S W^{d}+\frac{2 \varepsilon z[-a(1-\varepsilon)+(1-\varepsilon-z)]}{9 b(1-\varepsilon)^{2}}
\end{aligned}
$$

The feasible solutions must satisfy the drastic innovation condition, i.e., $\varepsilon>a-(1-z)$, the condition of non-negative cost, i.e., $1-\varepsilon-z \geq 0$, and the condition of non-negative output, i.e., $a-(1-\varepsilon-z) \geq 0$. Based on the drastic innovation condition and $\varepsilon \in[0,1]$, we get the range of parameter $a$ as $a \in[(1-\varepsilon-z), 2]$.

We first examine the licensor's environmental regime preference by observing the second term in Equation (6c) and find that when the market size is large, the licensor prefers the environmental standard regime, since a large market size causes $R^{m}-R^{m^{*}}<0$; on the contrary, given a small market size, the licensor prefers the emission tax regime, since a small market size causes $R^{m}-R^{m^{*}}>0$. The intuition behind this result is that the emission tax regime has an output distortion effect, which is small (large) when the market size is small (large). The output distortion effect also impacts the licensor's licensing revenue. Hence, the licensor prefers the emission tax (environmental standard) regime when the market size is small (large). We conclude the licensor's licensing preference in Proposition 2.

Proposition 2 No matter in a non-drastic innovation case or in a drastic innovation case, the domestic licensor's environmental regime preference depends on the market size. When the market size is large, the domestic 
innovator prefers the environmental standard regime to the emission tax regime; on the contrary, when the market size is small, the domestic innovator prefers the emission tax regime to the environmental standard regime.

We next consider the social planner's decision-making on an environmental policy by a competitive static analysis on $\Delta S S^{d}$ as follows:

$$
\frac{d \Delta S S^{d}}{d a}=\frac{(3 / 2)(1-\varepsilon)(1-\varepsilon-z)}{3 b(1-\varepsilon)^{2}}+\frac{(2 / 3) \varepsilon z(\varepsilon-1)}{3 b(1-\varepsilon)^{2}} \geq 0, \text { if } \varepsilon \in\left[0, \frac{9(1-z)}{9+4 z}\right]
$$

From the Equation (6d), we find that the conclusion in a drastic innovation case is the same as that in a non-drastic innovation case in which social welfare in the emission tax regime is higher than that in the environmental standard regime when the market size is large and the innovation size is small. There is an inverse conclusion when the market size and the innovator size are large.

Section 4 considers the cases of non-drastic and drastic innovation in which the patentee is a foreign innovator; Section 5 also considers the cases of non-drastic and drastic innovation, but when the patentee is a domestic innovator. The findings in these two sections are very different. In Section 4 the adoption of an environmental regime only depends on the market size; however, in Section 5 the adoption of an environmental regime not only depends on the market size, but also on the innovation size. In other words, Section 4 concludes that when the market size is large, social welfare in the emission tax regime is higher than that in the environmental standard regime; Section 5 has the same conclusion when the market size is large and the innovation size is small. Finally, we summarize the finding in Proposition 3 and arrange the social planner's and the domestic licensor's environmental regime preference in Table 6.

Proposition 3 No matter in a non-drastic innovation case or in a drastic innovation case, when the licensor is a foreign innovator, the adoption of an environmental regime only depends on the market size; when the licensor is a domestic innovator, the adoption of an environmental regime not only depends on the market size, but also on the innovation size.

Table 6. The social planner's and the domestic licensor's preference

\begin{tabular}{llllll}
\hline Model & Decision Maker & Market size & Innovation size & Non-drastic innovation & Drastic innovation \\
\hline Licensor is a foreign firm & Social planner & Large & - & Emission tax & Emission tax \\
& & Small & - & Environmental standard & \\
\hline Licensor is a domestic firm & Social planner & Large & Small & Emission tax & \\
& & & Large & Environmental standard \\
\cline { 2 - 5 } & Licensor & Large & - & Environmental standard & \\
& & Small & - & Emission tax & \\
\hline
\end{tabular}

From Table 6, we conclude that the environmental standard may not be a welfare-superior regime for Taiwan's adhesive tape manufacturing industry. This result is different from that in Naito and Ogawa (2009) who consider the relation between the environmental regime and the privatization degree. They conclude that the environmental standard is the optimal environmental regime no matter what the privatization degree is. We also conclude there is an environmental preference inconsistency between the patentee and the social planner when the innovator is a domestic firm.

\section{Concluding Remarks}

For the targets of green production and environmental friendliness, governments often use an emission tax regime and an environmental standard regime. According to the real observation in Taiwan, TEPA adopts the environmental standard regime to restrict VOCs emission being emitted from Taiwan's adhesive tape manufacturing industry. This industry's manufacturing firms also actively seek emission abatement technology so as to reach the TEPA's environmental standard. Some R\&D institutions such as TITRI or some firms such as $3 \mathrm{M}$ are willing to license emission abatement technology to Taiwan's adhesive tape manufacturing firms, because they earn the licensing revenue. We consider technology licensing in the environmental protection issue and we are interested in whether the environmental standard regime on Taiwan's adhesive tape manufacturing industry is a welfare-superior regime.

We conclude that the environmental standard regime adopted by TEPA for restricting VOCs emission being emitted form Taiwan's adhesive tape manufacturing industry may not be the welfare-superior environmental regime. This finding is very different with that in Naito and Ogawa (2009) who study the relationship between 
the environmental regime and the privatization degree. They conclude that social welfare in the environmental standard regime is higher than that in the emission tax regime no matter what the privatization degree is. We also find that there is an environmental preference inconsistency between the patentee and the social planner when the patentee is a domestic innovator.

Many previous papers study the optimal environmental regime. The real world phenomenon tells us that governments set up different environmental regimes with respect to different industries, such as TEPA adopting the environmental standard regime to regulate the adhesive tape manufacturing industry and it adopting the emission tax regime to regulate the cement manufacturing industry. In this paper we confirm that the environmental standard is indeed the welfare-superior regime for Taiwan's adhesive tape manufacturing industry. In the future, we can also confirm whether the emission tax is the welfare-superior regime for Taiwan's cement manufacturing industry.

\section{Acknowledgement}

The author appreciates financial support from Taiwan's National Science Council (NSC 101-2410-H-424 -012).

\section{References}

Arrow, K. J. (1962). Economic welfare and the allocation of resources for invention. In R. R. Nelson (Ed.), The Rate and Direction of Inventive Activity: Economic and Social Factors (pp. 609-625). Princeton University Press.

Bárcena-Ruiz, J. C., \& Garzó, M. B. (2006). Mixed oligopoly and environmental policy. Spanish Economic Review, 8, 139-160. http://dx.doi.org/10.1007/s10108-006-9006-y

Beladi, H., \& Chao, C. C. (2006). Does privatization improve the environment? Economics Letters, 93, 343-347. http://dx.doi.org/10.1016/j.econlet.2006.06.005

Brocas, P. (2003). Vertical integration and incentives to innovate. International Journal of Industrial Organization, 21, 457-488. http://dx.doi.org/10.1016/S0167-7187(02)00121-2

Buehler, S., \& Schmutzler, A. (2008). Intimidating competitors - Endogenous vertical integration and downstream investment in successive oligopoly. International Journal of Industrial Organization, 26, 247-265. http://dx.doi.org/10.1016/j.jindorg.2006.11.005

Chang, M. C. (2011). International technology transfer and market size: the case of an emerging economy. Journal of International and Global Economic Studies, 4, 59-73.

Chang, M. C., Hu, J. L., \& Tzeng, G. H. (2009). Decision making on strategic environmental technology licensing: fixed-fee versus royalty licensing methods. International Journal of Information Technology and Decision Making, 8, 609-624. http://dx.doi.org/10.1142/S0219622009003545

Ebert, U. (1992). Pigouvian taxes and market structure: the case of oligopoly and different abatement technologies. Finanzarchiv, 49, 154-166.

Ebert, U. (1998). Relative standards: a positive and normative analysis. Journal of Economics, 67, 17-38. http://dx.doi.org/10.1007/BF01227761

Helfand, G. (1991). Standards versus standards: the effect of different pollution restrictions. American Economic Review, 81, 622-634.

Kamien, M., \& Tauman, Y. (1984). The private value of a patent: a game theoretic analysis. Journal of Economics (Supplement), 4, 93-118.

Kamien, M., \& Tauman, Y. (1986). Fees versus royalties and the private value of a patent. Quarterly Journal of Economics, 101, 471-491. http://dx.doi.org/10.2307/1885693

Kamien, M., \& Tauman, Y. (2002). Patent licensing: the inside story. The Manchester School, 70, 7-15. http://dx.doi.org/10.1111/1467-9957.00280

Kamien, M., Oren, S., \& Tauman, Y. (1992). Optimal licensing of cost-reducing innovation. Journal of Mathematical Economics, 21, 483-508. http://dx.doi.org/10.1016/0304-4068(92)90036-7

Kato, K. (2006). Can allowing to trade permits enhance welfare in mixed oligopoly? Journal of Economics, 88 , 263-283. http://dx.doi.org/10.1007/s00712-006-0206-6

Kato, K. (2011). Emission quota versus emission tax in a mixed duopoly. Environmental Economics and Policy Studies, 13, 43-63. http://dx.doi.org/10.1007/s10018-010-0003-x 
Katsoulacos, Y., \& Xepapadeas, A. (1995). Environmental policy under oligopoly with endogenous market structure. Scandinavian Journal of Economics, 97, 411-420. http://dx.doi.org/10.2307/3440871

Katz, M., \& Shapiro, C. (1986). How to license intangible property. Quarterly Journal of Economics, 101, 567-589. http://dx.doi.org/10.2307/1885697

Kayalica, M. Ö., \& Lahiri, S. (2005). Strategic environmental policies in the presence of foreign direct investment. Environmental and Resource Economics, 30, 1-21. http://dx.doi.org/10.1007/s10640-004-0757-3

Kiyono, K., \& Okuno-Fujiwara, M. (2003). Domestic and international strategic interactions in environmental policy formation. Economic Theory, 21, 613-633. http://dx.doi.org/10.1007/s00199-002-0300-0

Lahiri, S., \& Ono, Y. (2007). Relative emission standard versus tax under oligopoly: the role of free entry. Journal of Economics, 91, 107-128. http://dx.doi.org/10.1007/s00712-006-0243-1

Li, C., \& Song, J. (2009). Technology licensing in a vertically differentiated duopoly. Japan and the World Economy, 21, 183-190. http://dx.doi.org/10.1016/j.japwor.2008.04.002

Lin, Y. S., Hu, J. L., \& Xla, P. C. (2012). Location choice and patent licensing. Manchester School (Forthcoming). http://dx.doi.org/10.1111/j.1467-9957.2011.02271.x

Matsushima, N. (2004). Technology of upstream firms and equilibrium product differentiation. International Journal of Industrial Organization, 22, 1091-1114. http://dx.doi.org/10.1016/j.ijindorg.2004.06.004

Mukherjee, A. (2007). Optimal licensing contract in an open economy. Economics Bulletin, 12, 1-6.

Naito, T., \& Ogawa, H. (2009). Direct versus indirect environmental regulation in a partially privatized mixed duopoly. Environmental Economics and Policy Studies, 10, 87-100.

Ohori, S. (2006a). Optimal environmental tax and level of privatization in an international duopoly. Journal of Regulatory Economics, 29, 225-233. http://dx.doi.org/10.1007/s11149-006-6037-0

Ohori, S. (2006b). Trade liberalization, consumption externalities and the environment: A mixed duopoly approach. Economics Bulletin, 17, 1-9.

Poddar, S., \& Sinha, U. S. (2004). On patent licensing in spatial competition. Economic Record, 80, 208-218. http://dx.doi.org/10.1111/j.1475-4932.2004.00173.x

Sen, D. (2002). Monopoly profit in a Cournot oligopoly. Economics Bulletin, 4, 1-6.

Sen, D. (2005). Fee versus royalty reconsidered. Games and Economic Behaviour, 53, 141-147. http://dx.doi.org/10.1016/j.geb.2004.09.005

Spulber, D. F. (1985). Effluent regulation and long run optimality. Journal of Environmental Economics and Management, 12, 103-116. http://dx.doi.org/10.1016/0095-0696(85)90021-X

Ulph, A. (1996). Environmental policy instruments and imperfectly competitive international trade. Environmental and Resource Economics, 7, 333-355. http://dx.doi.org/10.1007/BF00369623

Wang, H. (1998). Fee versus royalty licensing in a Cournot duopoly model. Economic Letters, 60, 55-62. http://dx.doi.org/10.1016/S0165-1765(98)00092-5

Wang, L. F. S., \& Wang, J. (2009). Environmental taxes in a differentiated mixed duopoly. Economic Systems, 33, 389-396. http://dx.doi.org/10.1016/j.ecosys.2009.08.002

\section{Note}

Note 1. If the innovation size is sufficiently large and only one firm gets the new technology, then the non-licensee will be kicked out of the market and the market structure becomes a monopoly in which the innovation size is called drastic innovation (Arrow, 1962). On the contrary, given a small innovation size and only one licensee, then the non-licensee still stay in the market and the market structure is a duopoly or an oligopoly in which the innovation size is called non-drastic innovation. 